\title{
Evaluation of Online Pedagogy among Higher Education International Students in China during the COVID-19 Outbreak
}

\author{
Blessing Funmi Komolafe ${ }^{1,2}$, Omorinola Tolulope Fakayode ${ }^{3}$, Adekunle Osidipe ${ }^{4}$, Fenyan Zhang1, \\ Xusheng Qian ${ }^{*}$
}

${ }^{1}$ Curriculum \& Pedagogy, Teacher Education College, Zhejiang Normal University, Jinhua, China

${ }^{2}$ Science Education Department, Faculty of Education, Adekunle Ajasin University, Ondo State, Nigeria

${ }^{3}$ International Centre for Educational Evaluation, Institute of Education, University of Ibadan, Ibadan, Oyo State, Nigeria

${ }^{4}$ Institute of African Studies, Zhejiang Normal University, Jinhua, China

Email: *jkyqxs@zjnu.cn

How to cite this paper: Komolafe, B. F., Fakayode, O. T., Osidipe, A., Zhang, F. Y., \& Qian, X. S. (2020). Evaluation of Online Pedagogy among Higher Education International Students in China during the COVID-19 Outbreak. Creative Education, 11, 2262-2279.

https://doi.org/10.4236/ce.2020.1111166

Received: October 7, 2020

Accepted: November 15, 2020

Published: November 18, 2020

Copyright $\odot 2020$ by author(s) and Scientific Research Publishing Inc. This work is licensed under the Creative Commons Attribution International License (CC BY 4.0).

http://creativecommons.org/licenses/by/4.0/

\begin{abstract}
Online-based pedagogy in teaching and learning has become the order of the day in this era of the COVID-19 outbreak. It became necessary to ensure that the pandemic did not cause a time gap in learning amongst students. Online learning involves the use of virtual platforms in the form of mobile and web applications for teaching and learning. Learning can take place using audio, visual and audio-visual means. Online learning has previously been used as a supplement for face-to-face interaction; however, it became the sole means of teaching during the pandemic and a novel development. A total of 273 international students across China engaging in online classes during COVID-19 outbreak volunteered to respond to the online questionnaire were involved in this study. The results of the descriptive statistic for the study were presented using charts and line plots. The research revealed the demographic details of the respondents, Wechat as the most prevalent platform used, perceived effectiveness of online classes, and other factors such as interest, engagement, participation, and problems encountered during online teaching among international students in China. The shortcomings that this research has brought to light are expected to enhance better online learning experiences post-COVID 19 in China and other parts of the world.
\end{abstract}

\section{Keywords}

Online-Based Pedagogy, Leaner's Interest, Leaner's Engagement, Leaner's Participation, International Students, COVID-19 


\section{Introduction}

Online pedagogy among international and indigene students in China became a necessity after the Corona Virus outbreak, which was first reported in Wuhan, Hubei Province, China in December 2019 (Dai et al., 2020; Gong et al., 2020). It was the only means to ensure continued learning (Hayes et al., 2020) among higher education students and it was embraced and adopted by the Chinese Government Education Board across China to adhere to disease control measures of social distancing and avoidance of gatherings and to avoid a time gap in the academic calendar. The spring semester slated for resumption by 17 th February 2020 was postponed, and online classes were adopted across China (Huaxia, 2020). Huaxia (2020) reported that the commencement of online classes as a control of the COVID-19 pandemic also promotes digitalization and informatization of teaching, such as the use of new applications such as the Rain Classroom app. Prior to the COVID-19 outbreak, which eventually turned to a pandemic, online learning in China and in most countries of the world had only been used as a supplement to face-to-face learning (Hew \& Cheung, 2014; Sobko et al., 2020) and not as a sole pedagogy approach.

With the prevalence of the pandemic and with predictions (Robert et al., 2020) that it could linger on for months and even more, online learning through various virtual platforms with a learning environment that allows the learner to learn and acquire knowledge in interactive mode (Deka \& Jena, 2017) is gradually replacing chalk and board classroom learning. China has over time made considerable achievements in terms of internationalization of higher education (Yang, 2014), through government funding (Frezghi \& Tsegay, 2019) and availability of various scholarship programmes such as the China Scholarship Council (CSC) scholarship, Belt and Road scholarship, Confucius Institute scholarship amongst others. It is germane to evaluate online pedagogy among international students since they are mostly from different educational backgrounds, while some could have previously engaged in online learning, others may not. Demographic details such as nationality, current degree, major and province were considered in the study. A previous study by Ruthotto et al. (2020) revealed that responses to virtual learning vary based on several factors. It is, therefore, crucial to evaluate the online pedagogical environment and factors such as learners' engagement, interest, associated problems and effectiveness as perceived by learners in the course of learning.

\section{Online-Based Pedagogy}

Pedagogy refers to the theory and practices of teaching in an educational context (LaVelle, Lovato, \& Stephenson, 2020). Technological advances hold a great deal of promise as online pedagogical tools (Kern, et al., 2004), and there is also a need for a multimedia specialist to develop a sound online-based pedagogy (van Rooij \& Zirkle, 2016). Online-based pedagogy is a kind of pedagogy that primarily revolves around technology-enhanced learning. Hill and France (2020) stu- 
died innovations in pedagogies; technology-enhanced learning was one of the eight kinds of innovative pedagogies.

The unique event of the COVID-19 pandemic has not only made technology-enhanced learning necessary; it has launched the world into "Digitalization and Informatization of teaching" and has showcase Online-Based Pedagogy as the only available teaching and learning option in this era (Charles et al., 2020). Several studies have shown that online-based instruction has successfully helped in learners' engagement facilitation, enhancing student learning, professional development and effective teaching with learning resources (Farhan et al., 2019; Sanders-Smith et al., 2016; Sun, 2016; Terry et al., 2018). Despite the successful uses of online-based instruction, there are still some problems encountered and negative impacts on learners. By considering the context of 919 (K-12) students taking online courses, Zheng et al. (2020) conducted research examining the impact of learner, instructor and course-level factors on online learning. The study found that online discussion negatively affected students' learning outcomes except if it was supported by project-based assignments and higher-level knowledge activities. Similarly, a systematic review on blended learning in Malaysia, which comprises face-to-face and online learning component instruction, revealed the challenges encountered; teachers and students find the use of technology for teaching and learning difficult and the problem of providing suitable instructional technology by the educational institution (Rasheed et al., 2019). Additionally, there are some risks associated with internet use, such as excessive engagement in specific online activities and other problems the learner can be exposed to (Orsolya et al., 2020).

Evidently, previous studies have shown the positive and negative aspects of online-based instruction and pointed to the fact that it should not be used as the only pedagogy in learning instruction. However, teaching and learning in the COVID-19 era depends solely on online-based instruction, and it is imperative to evaluate online-based learning during the COVID-19 in comparison to previous literature claims and seeing through the lens of an international student in China.

\subsection{Learner's Participation \& Engagement in Technology-Enhanced Instruction}

In enhancing teaching and learning processes, learners' participation is essential (Haniya \& Paquette, 2020). The study by Haniya and Paquette (2020) examined learners' massive online course participation, using participation patterns such as "Advanced, Balanced, Early, Limited, and Delayed Participation", and found two major factors that drive learners' participation (motivations and barriers), and their impacts vary with respect to the learners. In another study in which a social network analysis research technique was adopted, 57 college-level students participated in online learning activities that were assisted by assigned moderators; the study revealed that student participation had significant influences on interaction attractiveness (Xie, et al., 2014). In the context of measuring learners' 
participation in technology-enhanced instruction, it can be said that learners can choose to be passive or active in learning engagement.

Learner engagement is an indispensable requirement for learning and vital to academic achievement in online learning (Gallagher et al., 2016; Omar et al., 2012), and Haron et al. (2017) defines it as an active learner in learning activities. In the use of technology instruction in enhancing learners' activities, the virtual platform has to be efficient because the quality and type of online teaching can promote meaningful learners' engagement (Christopoulos et al., 2018; Eric, 2020; Warford, 2014). Dougherty and Andercheck (2014) studied the use of a virtual platform (Facebook) to engage learners in a large introductory course and revealed that the Facebook platform proved effective as a powerful tool for engaging learners.

Furthermore, in a systematic analysis review, Haron et al. (2017) found that in an e-learning community, collaborative learning that can foster interaction that will in turn lead to participatory engagement must comprise interactions of learners, interaction of educators and learners, interaction with content, and self-reflection. However, a book chapter raises a concern about learner engagement in technology in terms of digital software, socioeconomic and race-related achievement gaps (Lo \& Miller, 2020). Based on previous studies, learners' participation and engagement in technology-enhanced instruction must be considered alongside the type of digital software and socioeconomic and race-related factors in which this research clearly fills this gap.

\subsection{Learner's Interest Sustainability in Online Classes}

"Interest is a powerful motivational process that energizes learning" (Harackiewicz et al., 2016). Reflecting on the learning experience of a first-year otolaryngology residency student, a decline in the applicants for otolaryngology residency was revived by stimulation strategies that sustain learner interest ( $\mathrm{Hu}, 2019)$. On this note, sustaining learner interest in online classes requires some strategies, either from the learner, from the teacher or in kind of network use (Choi \& Park, 2014). Interest is powered by motivation in a learning process and is subject to change through learning activities (Nakazawa \& Ikeda, 2011). To this end, the learning activities in a normal face-to-face learning process differ from online classes (Nakamura et al., 2012), and how can learner activities on online classes be sustained? Recently, research carried out on "towards recommendation using learners' interest in social learning environment" rightly identifies fewer studies that were based on this research context (Lamia et al., 2020). Lamia et al. (2020) analyzed the learning environment and proposed a social interaction (users-users and users-resources)-based learning environment.

This study explored some indicators to measure learners' interest in online classes, which can help to identify factors that can sustain learners' interest during teaching and learning and recommendations for better ways to sustain learners' interest in online-based environments. Thus, the purpose of this research is to identify international students engaging in the online classes during 
COVID-19 outbreak demographic information and their study locations, online learning platforms adopted, and which is the most prevalent platform; the medium of pedagogy adopted; perceived effectiveness. To know maybe the adopted pedagogy encourages learners' participation, engagement and sustained learner's interest during teaching and learning. Besides, to know the problems encountered during online teaching and online pedagogy student preference. As the research outcome can strengthen the educational stakeholder such as school administrators, ministry of education to prepare for better online learning experiences for post-COVID 19 in China and other parts of the world.

\section{Methodology}

\subsection{Participants}

The population for the research comprises international students in China engaging in online class during the Covid-19 pandemic. Purposive sampling was used to select international students that were in China at the time of the study. This was because aside engaging in online classes; they were experiencing the outbreak first-hand. The questionnaires were administered online and sent to international students across China through academic groups, colleagues, and friends. The final samples were those that eventually responded to the questionnaire. A total of 273 international students responded to the questionnaire.

\subsection{Design and Procedure}

The instrument used for the study was the Pedagogy Measure in Virtual learning Questionnaire, which was constructed by the researchers. The questionnaire comprises items on demographic information of students (nationality, current degree, major and province), type of platforms used for online learning, medium of instruction (audio, visual or audio-visual), student engagement during online learning, problems with online learning, perceived effectiveness of online learning and sustained interest during online learning. The learner's engagement section asked questions relating to the learner's activities during the learning process with a Yes/No response format. Learners' interest during the online class considered items to determine how engrossed learners were in the online classes with a 4-scale response format. The perceived effectiveness section of the questionnaire compared the effectiveness of online learning to in-class learning in factors such as communication, sense of community, convenience, participation and interaction, meeting individual needs, aiding understanding and providing better explanation as perceived by the learners. The response formats (see Table 1 for review). For the section on the problems encountered in the course of the online classes, fifteen predetermined problems were listed, which were drawn using results from existing studies and literature on some of the problems associated with the use of technology-based learning. Respondents were asked to respond using yes or no to problems they personally encountered, which was not limited to a particular number of problems. 
The questionnaire was an online form that was distributed and filled electronically by respondents. The collection of data for the study spanned from March through May 2020.

\subsection{Results}

The demographic information of the respondents in the study.

Table 1 shows that 53 countries were represented in the study, with the majority (30) from Africa, followed by Asia (19) and Europe and North America with 2 each.

Figure 1 shows that $113(41.39 \%)$ of the respondents were undergraduates, 89 (32.6\%) were master's students and $71(26.01 \%)$ were doctoral students. There were more undergraduates than masters than doctor students.

Figure 2 shows that 108 (39.56\%) respondents were science majors, 18 (6.59\%) were in arts, 14 (5.13\%) were in humanities, 73 (26.74\%) were in engineering, $46(16.85 \%)$ were in social sciences and $14(5.13 \%)$ were in medical sciences. This implies that there are more international students in the sciences than engineering, social sciences, art, humanities, and medical sciences. This could be because the country of those international students requires such kind of talent, so they choose this major.

Figure 3 shows those 20 provinces, 3 municipalities and 1 autonomous city represented in the study.

Figure 4 shows that several platforms were used for online teaching, ranging from common platforms such as zoom, dingtalk, classin, wechat, tencent, QQ, skype, rain classroom, superstar and chaoxing. Other applications used rarely were MOOC, Big Blue Botton Virtual class, BBB (Better Business Bureau), Tang class, Twitter, Instagram, E-mail, Coursera, Welink, Ice, Sakia, Zjoooc.cn, Ingke and Microsoft Team. Several people also indicated that they adopted more than one of the applications, with some using approximately 4 simultaneously. The distribution of application usage shows that the most widely used platform is WeChat, followed by tencent, Zoom, Dingtalk and QQ with equal proportions, Skype and classin. Other applications accounted for $8.07 \%$ accumulatively. WeChat is the most widely used platform because WeChat is the main social platform widely used across China.

The result represented by Figure 5 shows that 234 (85.71\%) had their classes using audio-visual, 26 (9.52\%) had classes using audio only and 13 (4.76\%) had classes using visual means only. The audio-visual is a generally more accepted medium of teaching because more senses are involved, and it helps to sustain interest and attention.

Table 2 shows that for communication, the majority of the respondents (156, 57.14\%) perceived that online teaching was less effective than in-class teaching; $91(33.33 \%)$ also agreed that the two forms of teaching were equally effective, while only a few $(26,9.53 \%)$ considered online teaching to be more effective than in-class teaching. This could be attributed to the fact that communication in online teaching is not very logical and sequential. 
Table 1. Demographic characteristics of the respondents (countries arranged by continent).

\begin{tabular}{|c|c|c|c|c|c|c|c|c|c|c|c|}
\hline \multirow[t]{2}{*}{ Africa } & \multicolumn{5}{|c|}{ Asia } & \multicolumn{3}{|c|}{ Europe } & \multicolumn{3}{|c|}{ North America } \\
\hline & $n$ & $\%$ & & $n$ & $\%$ & & $n$ & $\%$ & & $n$ & $\%$ \\
\hline Nigerian & 97 & 35.53 & Pakistan & 26 & 9.52 & UK & 1 & 0.37 & Jamaican & 1 & 0.37 \\
\hline Ghanaian & 23 & 8.42 & Indian & 6 & 2.20 & Ukraine & 1 & 0.37 & USA & 1 & 0.37 \\
\hline Liberian & 8 & 2.93 & Bangladeshi & 6 & 2.20 & & & & & & \\
\hline Rwandan & 18 & 6.59 & Yemeni & 3 & 1.10 & & & & & & \\
\hline Tanzanian & 6 & 2.20 & Kazakhstan & 2 & 0.73 & & & & & & \\
\hline South African & 4 & 1.47 & Iranian & 2 & 0.73 & & & & & & \\
\hline Ugandan & 4 & 1.47 & Korean & 2 & 0.73 & & & & & & \\
\hline Congolese & 6 & 2.20 & Azerbaijan & 1 & 0.37 & & & & & & \\
\hline Zambian & 5 & 1.83 & Syrian & 1 & 0.37 & & & & & & \\
\hline Zimbabwean & 11 & 4.03 & Japan & 1 & 0.37 & & & & & & \\
\hline Egyptian & 3 & 1.10 & Afghan & 1 & 0.37 & & & & & & \\
\hline Cameroonian & 2 & 0.73 & Nepal & 2 & 0.73 & & & & & & \\
\hline Kenyan & 2 & 0.73 & Palestinian & 1 & 0.37 & & & & & & \\
\hline Ethiopian & 4 & 1.47 & Sri Lanka & 2 & 0.73 & & & & & & \\
\hline Cape-verdian & 1 & 0.37 & Bahrain & 1 & 0.37 & & & & & & \\
\hline Madagascar & 1 & 0.37 & Nepalese & 1 & 0.37 & & & & & & \\
\hline Swaziland & 1 & 0.37 & Indonesia & 1 & 0.37 & & & & & & \\
\hline Sudanese & 3 & 1.10 & Filipino & 1 & 0.37 & & & & & & \\
\hline Gabonese & 1 & 0.37 & & & & & & & & & \\
\hline Senegalese & 1 & 0.37 & & & & & & & & & \\
\hline Malawian & 1 & 0.37 & & & & & & & & & \\
\hline Somalian & 1 & 0.37 & & & & & & & & & \\
\hline Namibian & 2 & 0.73 & & & & & & & & & \\
\hline Togolese & 2 & 0.73 & & & & & & & & & \\
\hline Equatorial Guinea & 1 & 0.37 & & & & & & & & & \\
\hline Niger & 1 & 0.37 & & & & & & & & & \\
\hline Libyan & 1 & 0.37 & & & & & & & & & \\
\hline Mozambique & 1 & 0.37 & & & & & & & & & \\
\hline Cote D'Ivoire & 3 & 1.10 & & & & & & & & & \\
\hline Malaysia & 1 & 0.37 & & & & & & & & & \\
\hline Guinea & 1 & 0.37 & & & & & & & & & \\
\hline
\end{tabular}




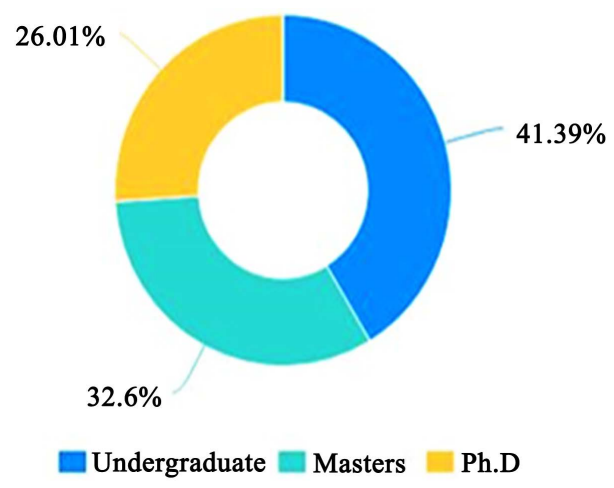

Figure 1. Demographic characteristics of the respondents (current degree).

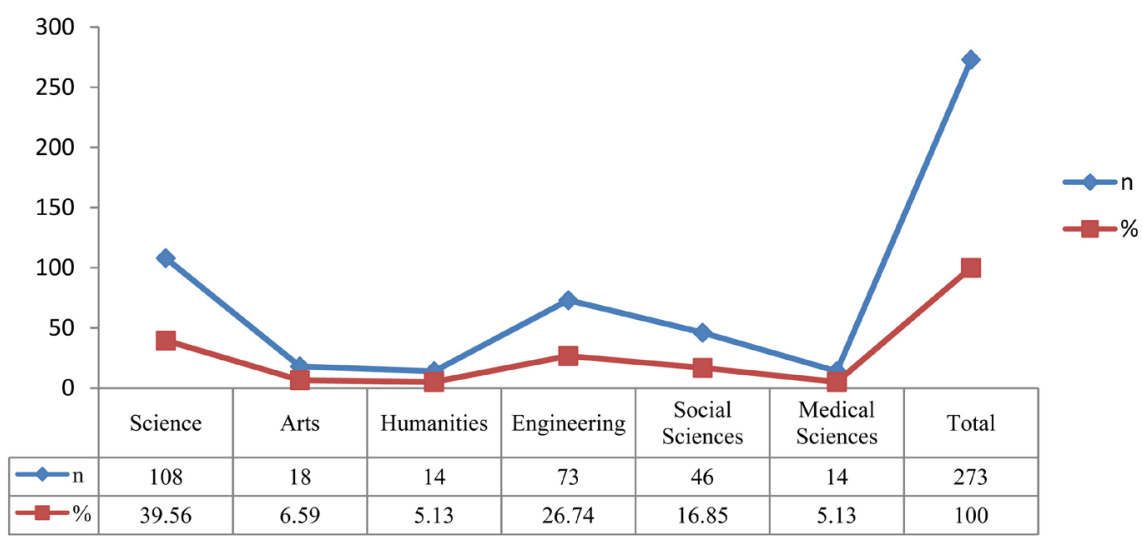

Figure 2. Demographic characteristics of the respondents (Major).

Table 2. Perceived effectiveness of online teaching compared to in-class learning.

\begin{tabular}{|c|c|c|c|c|c|c|c|c|c|c|}
\hline & \multicolumn{2}{|c|}{$\begin{array}{c}\text { Much } \\
\text { less effective }\end{array}$} & \multicolumn{2}{|c|}{$\begin{array}{l}\text { Somewhat } \\
\text { less effective }\end{array}$} & \multicolumn{2}{|c|}{$\begin{array}{l}\text { Equally } \\
\text { effective }\end{array}$} & \multicolumn{2}{|c|}{$\begin{array}{c}\text { Somewhat } \\
\text { more effective }\end{array}$} & \multicolumn{2}{|c|}{$\begin{array}{c}\text { Much more } \\
\text { effective }\end{array}$} \\
\hline & $\mathrm{N}$ & $\%$ & $\mathrm{~N}$ & $\%$ & $\mathrm{n}$ & $\%$ & $\mathrm{~N}$ & $\%$ & $\mathrm{n}$ & $\%$ \\
\hline Communication & 65 & 23.81 & 91 & 33.33 & 91 & 33.33 & 17 & 6.23 & 9 & 3.30 \\
\hline Sense of community & 62 & 22.71 & 94 & 34.43 & 91 & 33.33 & 21 & 7.69 & 5 & 1.83 \\
\hline Offering convenience & 29 & 10.62 & 54 & 19.78 & 106 & 38.83 & 40 & 14.65 & 44 & 16.12 \\
\hline $\begin{array}{l}\text { Promoting participation } \\
\text { and interaction }\end{array}$ & 53 & 19.41 & 94 & 34.43 & 90 & 32.97 & 19 & 6.96 & 17 & 6.23 \\
\hline Meeting individual needs & 53 & 19.41 & 89 & 32.60 & 94 & 34.43 & 22 & 8.06 & 15 & 5.49 \\
\hline $\begin{array}{l}\text { Aiding better } \\
\text { understanding }\end{array}$ & 44 & 16.12 & 94 & 34.43 & 104 & 38.10 & 17 & 6.23 & 14 & 5.13 \\
\hline $\begin{array}{c}\text { Providing } \\
\text { better explanation }\end{array}$ & 51 & 18.68 & 88 & 32.23 & 99 & 36.26 & 20 & 7.33 & 15 & 5.49 \\
\hline
\end{tabular}

For sense of community, the majority of the respondents $(156,57.14 \%)$ perceived that online teaching was less effective than in-class teaching; 91 (33.33\%) agreed that the two forms of teaching were equally effective, while only a few $(26,9.53 \%)$ considered online teaching to be more effective than in-class teaching. This could be because online teaching does not require any social interaction and therefore does not render any form of community sense. 


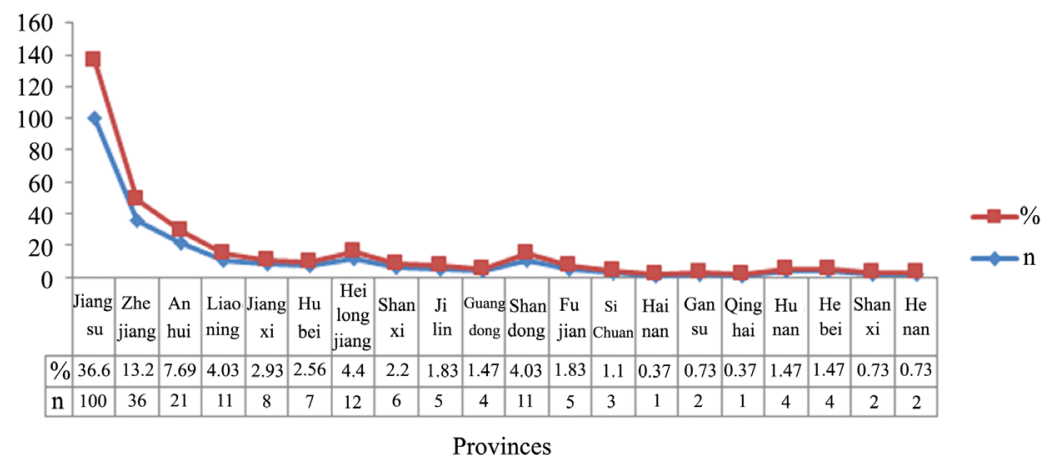

(a)

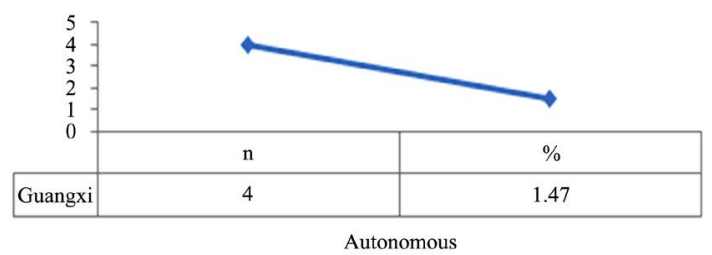

$\sim$ Guangx

(b)

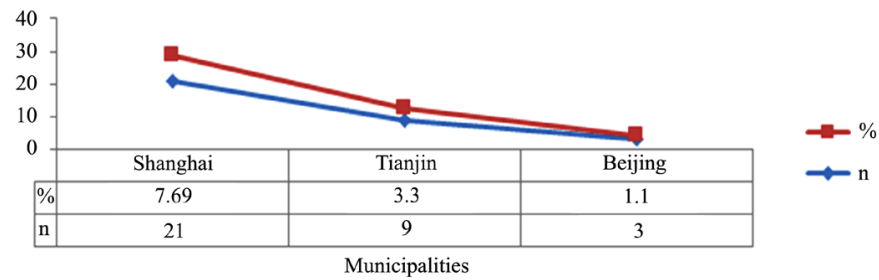

(c)

Figure 3. Demographic characteristics of the respondents (Categories of cities).

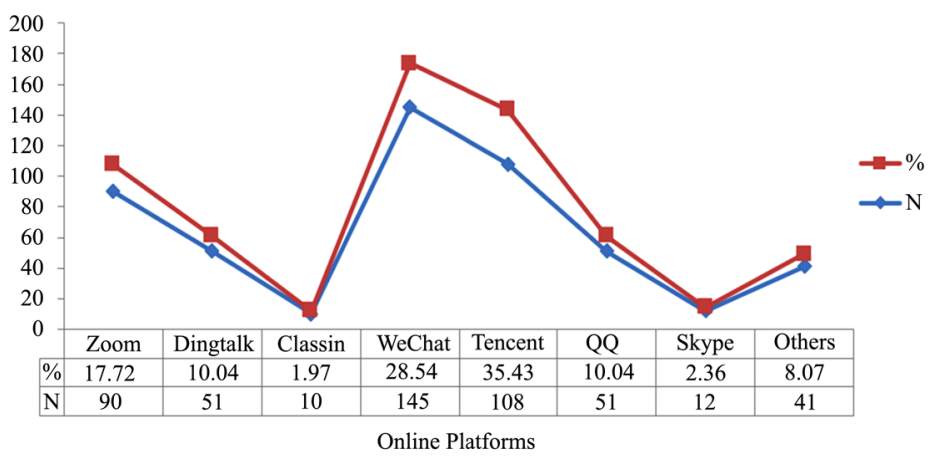

Figure 4. Online platforms adopted for online teaching.

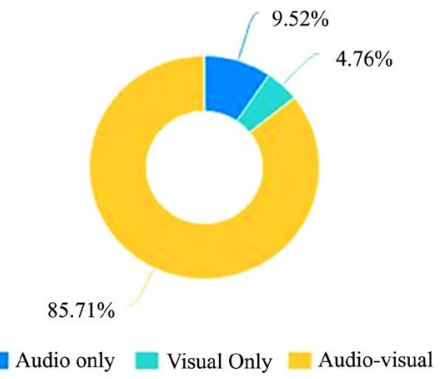

Figure 5. Medium of instruction. 
For offering convenience, $83(30.4 \%)$ of the respondents perceived that online teaching was less effective than in-class teaching, 106 (38.83\%) agreed that the two forms of teaching were equally effective, and 84 (30.77\%) considered online teaching to be more effective than in-class teaching. The result shows that an almost equal number of respondents agreed to online teaching and in-class teaching to be effective and less effective for offering convenience to students while studying. More respondents consider online teaching and in-class teaching to be equally effective.

For promoting participation and interaction, the majority of the respondents $(147,53.84 \%)$ perceived that online teaching was less effective than in-class teaching; 90 (32.97\%) agreed that the two forms of teaching were equally effective, while $36(13.19 \%)$ considered online teaching to be more effective than in-class teaching. This could be because online teaching does not require any social interaction and therefore does not promote participation among learners.

For meeting individual needs, the majority of the respondents (142, 52.01\%) perceived that online teaching was less effective than in-class teaching; 94 $(34.43 \%)$ agreed that the two forms of teaching were equally effective, while 37 (13.55\%) considered online teaching to be more effective than in-class teaching. This could be because the same pedagogy approach is delivered through online teaching, which gives no room for individuals and their specific needs.

To aid in better understanding, the majority of the respondents $(138,50.55 \%)$ perceived that online teaching was less effective than in-class teaching; 104 (38.1\%) agreed that the two forms of teaching were equally effective, while only 31 $(11.36 \%)$ considered online teaching to be more effective than in-class teaching.

To provide a better explanation, the majority of the respondents $(139,50.91 \%)$ perceived that online teaching was less effective than in-class teaching; 99 (36.26\%) agreed that the two forms of teaching were equally effective, while only a few $(35,12.82 \%)$ considered online teaching to be more effective than in-class teaching.

The results in Table 3 show that the majority of the respondents (202, $73.99 \%)$ ask questions during online classes, the majority $(226,82.78 \%)$ answer questions during online classes, and the majority $(247,90.48 \%)$ participate in activities given by teachers during online classes. Quite a number of the respondents 167 (61.17\%) also communicated with their peers during online classes. All these findings indicate that the majority of the students participate and are actively engaged in the online learning process.

The results in Table 4 show that the majority of the respondents (187, $68.49 \%)$ look forward to the next online class; however, 86 (31.5\%) do not look forward to the next class, which shows that their interest in the class has not been sustained. The result also shows that $115(42.12 \%)$ of the respondents would not participate in online classes if they had the choice, while 158 (57.88\%) would participate even when there are other options. This indicates that more respondents will choose to participate in online classes. The results show that the 
majority of the respondents $(216,79.12 \%)$ study related materials after the online class, while only a few $(57,20.88 \%)$ do not. This shows that their interest in the online classes is sustained for them to consider further studies. The majority of the respondents $(216,79.12 \%)$ preferred face-to-face interaction to online class, while a few $(57,20.88 \%)$ preferred online class-to-face interaction. The result shows that there are more respondents 146 (53.48\%) who are excited about online classes than 127 (46.52\%) who are not excited about it, even though the difference is not so much.

Table 5 shows the problems attributed to online learning as indicated by the respondents. The chart reveals that the problems encountered by a majority of the respondents (40\% and above) were increased distraction, difficulty paying attention, less motivation, less social interaction and technical issues, with technical issues being the most prevalent problem encountered. Other problems encountered by quite a number are less hands-on-experience, difficulty in reading other people's posts, information overload, difficulty keeping up with pace, academic dishonesty, difficulty asking questions, being stressful and difficulty retaining information. Problems encountered by only a few people are time consumption and difficulty in answering questions.

Figure 6 shows that $115(42.2 \%)$ would prefer in-class learning after their exposure to online learning, 30 (10.99\%) would prefer online learning, and 128

Table 3. Learner's participation and engagement.

\begin{tabular}{|c|c|c|c|c|}
\hline \multirow{2}{*}{ Items on participation and engagement } & \multicolumn{2}{|c|}{ Yes } & \multicolumn{2}{|c|}{ No } \\
\hline & $\mathrm{n}$ & $\%$ & $\mathrm{n}$ & $\%$ \\
\hline I ask questions during online classes & 202 & 73.99 & 71 & 26.01 \\
\hline I give answers to questions during online classes & 226 & 82.78 & 47 & 17.22 \\
\hline I take part in the activities given by my teacher during online classes & 247 & 90.48 & 26 & 9.52 \\
\hline I communicate with my peers during online classes & 167 & 61.17 & 106 & 38.83 \\
\hline
\end{tabular}

Table 4. Sustenance of learners' interest during teaching and learning.

\begin{tabular}{|c|c|c|c|c|c|c|c|c|}
\hline & \multicolumn{2}{|c|}{ Very true of me } & \multicolumn{2}{|c|}{ True of me } & \multicolumn{2}{|c|}{ Not true of me } & \multicolumn{2}{|c|}{ Not very true of me } \\
\hline & $n$ & $\%$ & $n$ & $\%$ & $n$ & $\%$ & $n$ & $\%$ \\
\hline $\begin{array}{l}\text { I look forward to the } \\
\text { next online class }\end{array}$ & 80 & 9.30 & 107 & 39.19 & 63 & 23.08 & 23 & 8.42 \\
\hline $\begin{array}{l}\text { If I have a choice I would not } \\
\text { participate in online classes }\end{array}$ & 45 & 16.48 & 70 & 25.64 & 111 & 40.66 & 47 & 17.22 \\
\hline $\begin{array}{l}\text { I study related materials } \\
\text { after the online class }\end{array}$ & 91 & 33.33 & 125 & 45.79 & 49 & 17.95 & 8 & 2.93 \\
\hline $\begin{array}{l}\text { I prefer face-to-face } \\
\text { interaction to online class }\end{array}$ & 138 & 50.55 & 78 & 28.57 & 42 & 15.38 & 15 & 5.49 \\
\hline $\begin{array}{l}\text { I am excited about online } \\
\text { classes and activities }\end{array}$ & 52 & 19.05 & 94 & 34.43 & 99 & 36.26 & 28 & 0.26 \\
\hline
\end{tabular}


Table 5. Problems encountered during online classes.

\begin{tabular}{|c|c|c|c|c|c|}
\hline \multicolumn{3}{|c|}{ Question } & Frequency & \multicolumn{2}{|l|}{$\%$} \\
\hline \multicolumn{3}{|c|}{ It is difficult to ask questions } & & & $20.51 \%$ \\
\hline \multicolumn{3}{|c|}{ It is difficult to answer questions } & & & $11.36 \%$ \\
\hline \multicolumn{3}{|c|}{ Technical issues } & & & $61.9 \%$ \\
\hline & \multicolumn{2}{|c|}{ Less social interaction } & & & $56.78 \%$ \\
\hline & \multicolumn{2}{|c|}{ Increased distraction } & & & $41.76 \%$ \\
\hline & \multicolumn{2}{|c|}{ Less motivation } & & & $46.89 \%$ \\
\hline & \multicolumn{2}{|c|}{ It is difficult to pay attention } & & & $44.32 \%$ \\
\hline & \multicolumn{2}{|c|}{ Less hands-on-experience } & & & $34.07 \%$ \\
\hline \multicolumn{3}{|c|}{ It is difficult to retain information } & & & $20.15 \%$ \\
\hline \multicolumn{3}{|c|}{ Academic dishonesty such as cheating } & & & $21.61 \%$ \\
\hline & \multicolumn{2}{|c|}{ Information overload } & & & $26.37 \%$ \\
\hline \multicolumn{3}{|c|}{ It is difficult to keep up with pace } & & & $26.01 \%$ \\
\hline & \multicolumn{2}{|c|}{ It is time consuming } & & & $12.09 \%$ \\
\hline & \multicolumn{2}{|c|}{ It is stressful } & & & $20.51 \%$ \\
\hline \multicolumn{3}{|c|}{$\begin{array}{l}\text { It is difficult to read other posts } \\
\text { and respond simultaneously }\end{array}$} & & & $33.33 \%$ \\
\hline \multicolumn{3}{|c|}{ Total } & 273 & & \\
\hline \multirow[t]{2}{*}{$\left.\begin{array}{r}400 \\
300 \\
200 \\
100 \\
0\end{array}\right]$} & & & & & \multirow{4}{*}{$\begin{array}{l}-\% \\
\sim N\end{array}$} \\
\hline & In-class learning & Online learning & $\begin{array}{l}\text { Combination of } \\
\text { In-class and } \\
\text { Online }\end{array}$ & Total & \\
\hline$\%$ & 42.12 & 10.99 & 46.89 & 100 & \\
\hline $\mathrm{N}$ & 115 & 30 & 128 & 273 & \\
\hline
\end{tabular}

Figure 6. Preference for medium of learning.

(46.89\%) would prefer a combination of the two modes of learning. This implies that more people prefer combinations of in-class and online. This could be because of the problem associated with online learning, but if combine, some of the problems could be easily solved with in-class learning, thereby providing an optimized learning process.

\section{Discussion}

Online-based pedagogy in teaching and learning has become the order of the day in this era of the COVID-19 outbreak. It became necessary to ensure that the pandemic did not cause a time gap in learning amongst students, in online pedagogical environment and factors such as learners' engagement, interest, asso- 
ciated problems and effectiveness as perceived by learners in the course of learning. The study evaluated the pedagogy of online teaching among international students in China during the outbreak of Coronavirus-19. In terms of the demographic details of the respondents, 53 nations were represented in the research, which implies that China is home to many international students and has made considerable efforts in the internationalization of higher education; the result is well aligned with Yang's (2014) study on China achievements in terms of the internationalization of higher education. There were more undergraduates taking online classes in the study, which was a result of taking all their classes online, and it was the only degree that is course based rather than research based, as in the case of master's and doctoral programmes. Similarly, there were more international students studying science-related subjects across the 20 provinces, 3 municipalities, and 1 autonomous city represented in the study because China is well known for technology advancement and scholarships are available for both science-based subjects and engineering, as shown in Statista. (2019) that in 2018, approximately 63,000 international students received scholarship from the Chinese government.

The evaluation of online platforms adopted for online teaching by international students in China during the COVID-19 pandemic, as this context of the research is very unique, it has provided insight into the various virtual platforms that can be adopted for learning and teaching processes (see Figure 4 for review). This finding confirms recent research on "virtual read-out", i.e., only virtual forms of teaching and learning available during the COVID-19 pandemic (Charles et al. 2020). The most prevalent platform used was WeChat. For the medium of pedagogy adopted, the medium adopted is perfectly digitalization and informatization. The findings support Huaxia (2020), who found that digitalization and informatization of teaching has been promoted in the era of the COVID-19 pandemic. Most international students had their classes using audio-visual, followed by audio only and visual-only. The findings confirm Espasa et al.'s (2019) research, which found that learners preferred video channels over audio or written channels in an online learning environment.

Regarding the effectiveness of online pedagogy as perceived by international students, communication during online teaching was less effective than in-class teaching, as communication in online teaching is not logical and sequential, sustaining learners' attention during online class needs to employ strategies such as variation in communities' network structures (Choi \& Park, 2014). Similarly, the sense of community of online teaching was perceived to be less effective than in-class teaching because there is no social interaction. This finding confirms prior research that explained that online-based learning requires the addition of project-based assignments and higher-level knowledge activities (Zheng et al. 2020), with learners having a sense of community. Another indicator for perceived effectiveness as used in the research is offering convenience; quite a number of international students consider online teaching and in-class teaching 
to be equally effective. The majority of the international students perceived participation and interaction, meeting individual needs, aiding better understanding, and providing better explanation during online teaching to be less effective than in-class teaching, which could be because the online classes were during a unique period when the teachers and learners were under environmental pressures. Thus, this result supports (Haniya \& Paquette, 2020) that motivations and barriers are factors that influence participation and interaction in online classes. Another barrier encountered is the adoption of the same pedagogy in delivering online teaching, which gave no room for learners' specific needs.

However, the reality of international students was done on participation and engagement, as shown in Table 3 probably because they need to engage online, which is against their perception about online classes, as shown in Table 2, that perceived participation and interaction in online teaching was less effective than in-class teaching. The majority of the respondents ask questions during online classes, give answers to questions during online classes, take part in activities given by the teachers during online classes and quite a number of the respondents also communicate with their peers during online classes. Thus, these findings on promoting meaningful learners' engagement in the virtual platform were in accordance with (Christopoulos et al., 2018; Eric, 2020; Warford, 2014).

Lamia et al. (2020) rightly identified fewer studies that were based on students' interest in online learning. The results on the sustainability of international students' interest during online classes during the COVID-19 pandemic reveal that learners' interest is sustained because many of the respondents reported that they would participate in online classes even when there are other options. A future study could examine various activities carried out on the virtual platforms that made them look forward to the next online class. Even though international students were excited about online classes, they still prefer face-to-face interaction with an online class.

For the problems encountered during online teaching, the major problems encountered were increased distraction, difficulty in paying attention, less motivation, less social interaction and technical issues, with technical issues being the most prevalent . This finding supports prior research that reported that technical issues were encountered by learners and teachers (Rasheed et al., 2019) and excessive engagement in specific online activities such as gambling, video gaming, and watching pornography during the COVID-19 pandemic that can cause distraction (Orsolya et al., 2020).

Finally, considering the medium of learning that students prefer after their exposure to online learning, the larger percentage of international students, as shown in Figure 6, prefer a combination of in-class and online learning, probably because of the problems associated with online learning. This is in line with Zheng et al. (2020), who found that online discussion negatively affected students' learning outcomes unless it had been supported by project-based assignments and higher-level knowledge activities. This finding hence suggests the 
possibility of combining in-class and online classes in the post-COVID-19 period.

\section{Conclusion}

In conclusion, as the global community begins to adjust to the post-COVID19 new normal life and the reality that it will be around for a while as humans carry out their activities, it becomes imperative for educational institutions to adopt measures that address the shortcomings of online education platforms and ensure that effective learning experiences and outcomes are achieved. While the shortcomings may be partly due to the use of the virtual learning environment in full deployment during an emergency situation, its adoption has enabled educational practitioners to experience first-hand the advantages and shortcomings that this research has brought to the light. The use of virtual learning will continue to be very relevant in the new normal life; therefore, educational practitioners need to keep abreast of strategies and approaches to improve virtual delivery of teaching and learning without sacrificing quality and content. On the other hand, teachers will be placed on new challenging pedestals as they will be faced with demands for innovation and mastery in the use of the virtual learning environment in the post-COVID19 new normal life. With the findings in this research, teachers and learners in higher institutions and other stakeholders in education such as Ministry of Education, school administrators should prepare ahead for a transformative learning environment that would involve an integration of both virtual and traditional learning platforms to enhance learning experience as well as promote good learning outcomes in learners.

\section{Acknowledgements}

The authors acknowledged the funding of Chinese Government Scholarship.

\section{Conflicts of Interest}

The authors declare no conflicts of interest regarding the publication of this paper.

\section{References}

Charles, H. L., Anandh, G. R., Patricia, T. A., Chia-Shang, J. L., Vishal, P., John, L. G., Paul, E. K., \& Jay, A. (2020). Virtual Read-Out: Radiology Education for the 21st Century during the Covid-19 Pandemic. Academic Radiology, 27, 872-881.

Choi, S., \& Park, H. W. (2014). Networking Interest and Networked Structure. Social Science Computer Review, 33, 145-162. https://doi.org/10.1177/0894439314527054

Christopoulos, A., Conrad, M., \& Shukla, M. (2018). Interaction with Educational Games in Hybrid Virtual Worlds. Journal of Educational Technology Systems, 46, 385-413. https://doi.org/10.1177/0047239518757986

Dai, W. C., Zhang, H. W., Yu, J., Xu, H. J., Chen, H., Luo, S. P., Lin, F. et al. (2020). CT Imaging and Differential Diagnosis of Covid-19. Canadian Association of Radiologists Journal, 71, 195-200. https://doi.org/10.1177/0846537120913033 
Deka, M., \& Jena, A. K. (2017). Effects of ICT Assisted Real and Virtual Learning on the Performance of Secondary School Students. International Journal of Research, 4, 1405-1420.

Dougherty, K. D., \& Andercheck, B. (2014). Using Facebook to Engage Learners in a Large Introductory Course. Teaching Sociology, 42, 95-104.

https://doi.org/10.1177/0092055X14521022

Eric, R. C. (2020). COVID-19 and Educational Engagement. Journal of Oral and Maxillofacial Surgery.

Espasa, A., Mayordomo, R. M., Guasch, T., \& Martinez-Melo, M. (2019). Does the Type of Feedback Channel Used in Online Learning Environments Matter? Students' Perceptions and Impact on Learning. Active Learning in Higher Education. https://doi.org/10.1177/1469787419891307

Farhan, W., Razmak, J., Demers, S., \& Laflamme, S. (2019). E-Learning Systems versus Instructional Communication Tools: Developing and Testing a New e-Learning User Interface from the Perspectives of Teachers and Students. Technology in Society, 59, Article ID: 101192. https://doi.org/10.1016/j.techsoc.2019.101192

Frezghi, T. G., \& Tsegay, S. A. (2019). Internationalisation of Higher Education in China: A Critical Analysis. Social Change, 49, 643-658. https://doi.org/10.1177/0049085719886693

Gallagher, T. L., Bennett, S., Keen, D., \& Muspratt, S. (2016). Examining Learner Engagement Strategies. Teacher Education and Special Education: The Journal of the Teacher Education Division of the Council for Exceptional Children, 40, 51-64. https://doi.org/10.1177/0888406416654213

Gong, F., Xiong, Y., Xiao, J., Lin, L., Liu, X., Wang, D., \& Li, X. (2020). China’s Local Governments Are Combating COVID-19 with Unprecedented Responses-From a Wenzhou Governance Perspective. Frontiers of Medicine, 14, 220-224.

https://doi.org/10.1007/s11684-020-0755-Z

Haniya, S., \& Paquette, L. (2020). Understanding Learner Participation at Scale: How and Why. E-Learning and Digital Media, 17, 236-252.

https://doi.org/10.1177/2042753019900963

Harackiewicz, J. M., Smith, J. L., \& Priniski, S. J. (2016). Interest Matters: The Importance of Promoting Interest in Education. Policy Insights from the Behavioral and Brain Sciences, 3, 220-227. https://doi.org/10.1177/2372732216655542

Haron, H., Natrah Aziz, N. H., \& Harun, A. (2017). A Conceptual Model Participatory Engagement within e-Learning Community. Procedia Computer Science, 116, 242-250. https://doi.org/10.1016/j.procs.2017.10.046

Hayes, S., Jopling, M., Hayes, D., Westwood, A., Tuckett, A., \& Barnett, R. (2020). Raising Regional Academic Voices (Alongside Data) in Higher Education Debate. Post Digital Science Education. https://doi.org/10.1007/s42438-020-00131-6

Hew, K. F., \& Cheung, W. S. (2014). Introduction. In Using Blended Learning (pp. 1-15). Springer Briefs in Education, Singapore: Springer.

https://doi.org/10.1007/978-981-287-089-6

Hill, J., \& France, D. (2020). Innovative Pedagogies. In International Encyclopedia of Human Geography (pp. 331-339). Amsterdam: Elsevier. https://doi.org/10.1016/B978-0-08-102295-5.10657-2

$\mathrm{Hu}$, A. (2019). Reflections: Starting an Otolaryngology Medical Student Interest Group. Otolaryngology-Head and Neck Surgery, 162, 155-156.

https://doi.org/10.1177/0194599819886121

Huaxia (2020). China Focus: Schools Start Online Courses as Epidemic Control Post- 
pones New Semester. Xinhuanet.

http://www.xinhuanet.com/english/2020-02/17/c 138792006.htm

Lamia, M., Hafidi, M., \& Aouidi, S. (2020). Towards Recommendation Using Learners' Interest in Social Learning Environment. In M. Ben Ahmed, A. Boudhir, D. Santos, M. El Aroussi, \& İ. Karas (Eds.), Innovations in Smart Cities Applications Edition 3. SCA 2019 (pp. 183-199). Lecture Notes in Intelligent Transportation and Infrastructure, Cham: Springer. https://doi.org/10.1007/978-3-030-37629-1 15

LaVelle, J. M., Lovato, C., \& Stephenson, C. L. (2020). Pedagogical Considerations for the Teaching of Evaluation. Evaluation and Program Planning, 79, Article ID: 101786. https://doi.org/10.1016/j.evalprogplan.2020.101786

Lo, S. R., \& Miller, A. L. (2020). Learning Behaviors and School Engagement: Opportunities and Challenges with Technology in the Classroom. In Technology and Adolescent Health: In school and Beyond (pp. 79-113). Cambridge, MA: Academic Press. https://doi.org/10.1016/B978-0-12-817319-0.00004-9

Nakamura, K., Kakusho, K., Shoji, T., \& Minoh, M. (2012). Investigation of a Method to Estimate Learners' Interest Level for Agent-Based Conversational e-Learning. In S. Greco, B. Bouchon-Meunier, G. Coletti, M. Fedrizzi, B. Matarazzo, \& R. R. Yager (Eds.), Advances in Computational Intelligence. IPMU 2012 (pp. 425-433). Communications in Computer and Information Science, Vol. 298, Berlin: Springer. https://doi.org/10.1007/978-3-642-31715-6 45

Nakazawa, M., \& Ikeda, M. (2011). A Method to Analyze Learners' Interest Changes with Concept Maps. In T. Theeramunkong, S. Kunifuji, V. Sornlertlamvanich, \& C. Nattee (Eds.), Knowledge, Information, and Creativity Support Systems (pp. 144-154). Lecture Notes in Computer Science, Vol. 6746, Berlin: Springer.

Omar, N. D., Hassan, H., \& Atan, H. (2012). Student Engagement in Online Learning: Learners Attitude toward e-Mentoring. Procedia-Social and Behavioral Sciences, 67, 464-475. https://doi.org/10.1016/j.sbspro.2012.11.351

Orsolya, K., Marc, N. P., Dan, J. S., Daniel, L. K., David, C. H., John, B. S., Mark, D. G., Biljana, G., Joël, B., Matthias, B., Max, W. A., Samuel, R. C., Ornella, C., Julius, B., Célia, M. D. S., Christian, M., Christine, L., Edna, G., Elisa, W., Giovanni, M., Hae, K. L., Hans-Jürgen, R., Jesús, C., Afarin, R., Susumu, H., Jose, M. M., Joseph, Z., Luca, P., Susanne, W., Naomi, F., \& Zsolt, D. (2020). Preventing Problematic Internet Use during the COVID-19 Pandemic: Consensus Guidance. Comprehensive Psychiatry, 100, Article ID: 152180.

Rasheed, R. A., Kamsin, A., \& Abdullah, N. A. (2019). Challenges in the Online Component of Blended Learning: A Systematic Review. Computers \& Education, 144, Article ID: 103701. https://doi.org/10.1016/j.compedu.2019.103701

Robert, C. C., Guy, T. C., Kaitlin, M. P., Brandon, W. P., Diane, F. H., Adnan, A. A., \& Timothy, J. V. (2020). Using Technology to Maintain the Education of Residents during the COVID-19 Pandemic. Journal of Surgical Education, 77, 729-732.

Ruthotto, I., Kreth, Q., Melkers, J., Stevens, J., \& Clare, T. (2020). Lurking and Participation in the Virtual Classroom: The Effects of Gender, Race, and Age among Graduate Students in Computer Science. Computers \& Education, 151, Article ID: 103854. https://doi.org/10.1016/j.compedu.2020.103854

Sanders-Smith, S. C., Smith-Bonahue, T. M., \& Soutullo, O. R. (2016). Practicing Teachers' Responses to Case Method of Instruction in an Online Graduate Course. Teaching and Teacher Education, 54, 1-11. https://doi.org/10.1016/j.tate.2015.11.015

Sobko, S., Unadkat, D., Adams, J., \& Hull, G. (2020). Learning through Collaboration: A Networked Approach to Online Pedagogy. E-Learning and Digital Media, 17, 36-55. 
https://doi.org/10.1177/2042753019882562

Statista (2019). Number of Foreign Students Studying in China from 2009 to 2018, by Source of Funding.

https://www.statista.com/statistics/251213/number-of-foreign-students-studying-in-ch ina-by-source-of-funding

Sun, J. (2016). Multi-Dimensional Alignment between Online Instruction and Course Technology: A Learner-Centered Perspective. Computers \& Education, 101, 102-114. https://doi.org/10.1016/j.compedu.2016.06.003

Terry, V. R., Terry, P. C., Moloney, C., \& Bowtell, L. (2018). Face-to-Face Instruction Combined with Online Resources Improves Retention of Clinical Skills among Undergraduate Nursing Students. Nurse Education Today, 61, 15-19. https://doi.org/10.1016/j.nedt.2017.10.014

van Rooij, S. W., \& Zirkle, K. (2016). Balancing Pedagogy, Student Readiness and Accessibility: A Case Study in Collaborative Online Course Development. The Internet and Higher Education, 28, 1-7. https://doi.org/10.1016/j.iheduc.2015.08.001

Warford, M. K. (2014). Toward a Framework for Evaluating Online Instruction in Higher Education. Journal of Educational Technology Systems, 42, 333-353. https://doi.org/10.2190/ET.42.4.b

Xie, K., Yu, C., \& Bradshaw, A. C. (2014). Impacts of Role Assignment and Participation in Asynchronous Discussions in College-Level Online Classes. The Internet and Higher Education, 20, 10-19. https://doi.org/10.1016/j.iheduc.2013.09.003

Yang, R. (2014). China's Strategy for the Internationalization of Higher Education: An Overview. Frontiers of Education in China, 9, 151-162. https://doi.org/10.1007/BF03397011

Zheng, B., Lin, C.-H., \& Kwon, J. B. (2020). The Impact of Learner-, Instructor-, and Course-Level Factors on Online Learning. Computers \& Education, 150, Article ID: 103851. https://doi.org/10.1016/j.compedu.2020.103851 